\title{
Evidence for the involvement of the GABA-ergic pathway in the anticonvulsant and antinociception activity of Propoxazepam in mice and rats
}

\author{
Mykola Golovenko', Anatoliy Reder', Sergey Andronati ${ }^{1}$, Vitalii Larionov ${ }^{1}$ \\ 1 Bogatsky Physical-chemical Institute of NAS, Odessa, Ukraine \\ Golovenko M, Reder A, Andronati S, Larionov V. Evidence for the involvement of the GABA-ergic pathway in the anticonvulsant and \\ antinociception activity of Propoxazepam in mice and rats. J Pre-Clin Clin Res. 2019; 13(3): 99-105. doi: 10.26444/jpccr/110430
}

\begin{abstract}
I Abstract
Introduction. Propoxazepam (3-alcoxyderivative of 1.4-benzodiazepine), in the tail-flick test and picrotoxin-induced convulsions showed significant analgesic and antiepileptic activity. Flumazenil (GABA antagonist) reduced its analgesic action, although antiseizure activity was changed slightly. As specific propoxazepam actions are anticonvulsant (1 subtype GABAA-R) and analgesic ( 2 subtype GABAA-R in the spinal cord), it can be suggested that the substance has no abuse-related side-effects.

Materials and method. The possible involvement of the GABA system in the antinociceptive effect of propoxazepam was examined by administering flumazenil ( 1 and $10 \mathrm{mg} / \mathrm{kg}$, i.p.), a selective GABA- receptor antagonist, 30 min prior to propoxazepam (1.8 and $10 \mathrm{mg} / \mathrm{kg}$, orally) in rats. Picrotoxin solution $(6.5 \mathrm{mg} / \mathrm{kg}, 95 \%$ of lethality effect in mice) was injected subcutaneously $30 \mathrm{~min}$ after propoxazepam administration. Flumazenil was administered intraperitoneally 0.5 hour prior to propoxazepam administration. Time counting was starting from the convulsant injection and during the supervision time, the number of myoclonic convulsions and tonic extensia, time of their onset, as well as time to lethal effect (survival time), were registered.

Results. Flumazenil and propoxazepam antiseizure effect in the picrotoxin-induced seizures test were estimated as $5.24 \pm 2.38$ and $0.37 \pm 0.07 \mathrm{mg} / \mathrm{kg}$. Antiseizure effect of propoxazepam was reduced with flumazenil administration. Flumazenil (1 mg/ $\mathrm{kg}$ ) had no effect in tail-flick test but abolished the antinociceptive action of propoxazepam (tail flick latency period changes were $-1.6 \%$ and +55.1 , compared to control and propoxazepam alone administration, respectively).

Conclusions. The mechanism of propoxazepam antiseizure and antinociceptive actions are GABA-R determined. Analgesic action mechanism assumes additional biotargets involvement.
\end{abstract}

\section{Key words}

rats, mouse, propoxazepam, flumazenil, picrotoxin, tail-flick test

\section{INTRODUCTION}

Antiepileptic drugs act on different molecular targets, selectively changing the excitability of neurons in such a way that the neuronal activity associated with attacks is blocked without disturbing the normal activity required to transmit signals between neurons. Various mechanisms can lead to reducing the excitability of the neurons of the epileptogenic focus. Basically, they consist either in inhibiting the activating neurons, or in activating depressing nerve cells, i.e., they are reduced to three major pharmaconeurophysiological effects: relief of GABA or glycine dependent transmission, reduction of excitatory (glutamate or aspartate) transmission, and nonspecific modification of ion currents (sodium, calcium, and potassium channels). At the same time, it is believed that the most effective control of seizure readiness is realized precisely because of GABAergic mechanisms [1,2].

Almost since their introduction, there has been interest to the therapeutic application of the benzodiazepines for the management of pain. As with many other drugs initially developed and studied for indications other than

Address for correspondence: Vitalii Larionov, Bogatsky Physical-chemical Institute of NAS of Ukraine, Lyustdorfskaya doroga 86, 65080, Odessa, Ukraine E-mail: Ivb_78@ukr.net

Received: 23.04.2019; accepted: 02.07.2019; first published: 20.09.2019 pain, conclusive data regarding the analgesic activity of benzodiazepines are lacking. A relevant aspect of neuroplastic changes in inflammatory and neuropathic conditions is the reduction in inhibitory glycinergic and GABAergic control of dorsal horn neurons: a reduction in the $\mathrm{GABA}_{\mathrm{A}}$-mediated endogenous inhibitory control within the central nervous system leads to exaggerated pain and hyperalgesia [3]. Potentiation of GABA receptor-mediated synaptic inhibition by benzodiazepines reverses pathologically increased pain sensitivity in animal studies [4].

A number of 3-substituted 1,4-benzodiazepines have been synthesized at the Physico-Chemical Institute of the National Academy of Sciences of Ukraine, and their structureactivity relationships studied. Their pharmacological effect was unusual, because unlike most drugs in this class, in the models of nociceptive and neuropathic pain these substances showed significant analgesic activity [5]. One of them, Propoxazepam, 7-bromo-5-(o-chlorophenyl)3-propoxy-1,2-dihydro-3H-1,4-benzodiazepin-2-one, is considered a promising drug and is undergoing preclinical trials [6]. Similar to gabapentin and pregabalin, which are well-known drugs used in general medical practice in the treatment of neuropathic pain [7], propoxazepam also has an anticonvulsant effect $[8,9]$, which explains the analgesic component of the pharmacological spectrum 


\section{OBJECTIVE}

The aim of the study was to clarify and determine the mechanism of the anticonvulsant and analgesic effects action of propoxazepam, and the influences of flumazenil on this action, and to discover whether flumazenil was able to modify or prevent the anticonvulsant effect (picrotoxin test in mice) and antinociceptive effect of propoxazepam in the tail-flick test in rats.

\section{MATERIALS AND METHOD}

Drugs and chemicals. Propoxazepam was synthesized according to the method described in [10]. The structure of the substance was determined and approved by a complex of physicochemical methods (IR and mass spectroscopy, as well as X-ray diffraction analysis). Chemical purity was confirmed by elemental analysis (99\%). Picrotoxin (Sigma) was used in the study as an convulsion-inducing agent.

Animals. Rats and mice were obtained from the animal house of the Institute of Pharmacology and Toxicology NAMS of Ukraine. Male and non-pregnant female rats (200-220 g) and male and female (non-pregnant) mice (25-30 g)), were housed in a temperature and light-controlled room $\left(24.0 \pm 2{ }^{\circ} \mathrm{C} ; 12\right.$ $\mathrm{h}$ light/dark cycle). Before starting the experiments, animals were randomly selected, marked on the tail for individual identification, and kept in their cages for 5 days to allow for acclimatization to laboratory conditions. The experiments were carried out according to the recommendations of the Committee for Research and Ethical Issues of the IASP (1983), and approved by the Regional Ethical Committee for animal research. Every effort was made to minimize animal suffering and to reduce the number of animals used.

Anticonvulsant and antinociceptive activity test - tail-flick test. The tail flick latency, defined by the time (in seconds) of withdrawal of the tail from a radiant heat source, according to [11], was measured via the use of a semiautomatic device (tail flick unit, Ugo Basil, Italy). After the placement of the rat tail into the apparatus in accordance with the procedure and activation of the apparatus at $55 \%$ power, the period required for tail flicking was calculated as the tail-flick period. Constant heat intensity was applied to the dorsum of the upper third of rat tail, and when the rat flicked its tail in response to the noxious thermal stimulus, both the heat source and the timer stopped automatically. A cut off-time of 22 seconds (3-4 times more than the basal tail-flick period) was imposed to prevent any injury to the tail. All the tests were repeated 3 times at intervals of 5 min between each application. The nociceptive threshold was observed before the study, and 1, 2, 4 and 6 hours after drug administration

The possible involvement of the GABA system in the antinociceptive effect of propoxazepam was examined by flumazenil injection ( 1 and $10 \mathrm{mg} / \mathrm{kg}$, i.p.), a selective GABAreceptor antagonist, $30 \mathrm{~min}$ prior to the administration of propoxazepam (1.8 and $10 \mathrm{mg} / \mathrm{kg}$, orally). Tail immersion latencies were then measured at 0 and $120 \mathrm{~min}$.

Picrotoxin-induced convulsions. The anticonvulsant effect of propoxazepam was evaluated on mice as the relative number of surviving animals that were recorded
2 hours after the convulsant administration. The tested compound was administered intraperitoneally (in a Tween-80 emulsion) [8,9]. Chemoconvulsant solution (picrotoxin $6.5 \mathrm{mg} / \mathrm{kg}$ ) is dose that causes lethal effects in $95 \%$ of tested animals was administered subcutaneously to animals (6-8 animals in each experimental group) $30 \mathrm{~min}$ after propoxazepam administration. Flumazenil was administered intraperitoneally 0.5 hour prior to propoxazepam administration. Time count was started from the convulsive agent injection and the following indicators were recorded: myoclonic convulsions, generalized seizures (as tonic extensia) and the time of their onset, as well as the total duration until the lethal effect (time of survive). The lethal effect estimation was determined in alternative forms (presence or absence of effect) and the protective effect $\left(\mathrm{ED}_{50}\right.$ value; probit method [8]) was determined as the relative quantity of surviving animals. Animals were divided onto 3 groups: 1) propoxazepam $\mathrm{ED}_{50}$ determination - 55 animals, 2) 18 animals with only flumazenil administration for $\mathrm{ED}_{50}$ determination, and 3) 24 animals for concomitant administration of propoxazepam and flumazenil. The change of $\mathrm{ED}_{50}$ was evidence of substances interaction with GABA-R.

Statistical analysis. The data were presented as a relative number (partial contribution, $M \pm m$ ) of total convulsive episodes. The significance of the differences in indices of convulsive action between the control and experimental groups (after a preliminary analysis for compliance with the normal distribution law), as well as the final experimental data, were evaluated using the unpaired Student's $t$ test, or by nonparametric statistics (Wilcoxon-Mann-Whitney test). Differences of $\mathrm{P}<0.05$ were regarded statistically significant.

The dose-effect curve slope was calculates as $\mathrm{S}=$ $\left(\mathrm{ED}_{82} / \mathrm{ED}_{50}+\mathrm{ED}_{50} / \mathrm{ED}_{18}\right) 0.5$, where $\mathrm{ED}_{18}, \mathrm{ED}_{50}$ and $\mathrm{ED}_{82}-$ calculated doses corresponding to the effect of $18 \%, 50 \%$ or $82 \%$ of animals (doses in the range $\pm 1 \mathrm{~s}$ ).

\section{RESULTS}

Effects of flumazenil and propoxazepam on picrotoxininduced convulsions in mice. As the experiments results show (Tab. 1), flumazenil exhibits anticonvulsive action in antagonism with picrotoxin only at high doses $\left(\mathrm{ED}_{50}=5.24 \pm 2.38 \mathrm{mg} / \mathrm{kg}\right)$.

Propoxazepam in this test had an $\mathrm{ED}_{50} 0.37 \pm 0.07 \mathrm{mg} / \mathrm{kg}$. There were also substantial differences in the curve slope (2.2 and 0.64 , respectively), which proves the higher sensitivity of the animal population to propoxazepam, compared to flumazenil.

Table 1. Mean effective dose of compounds (intraperitoneal administration) on antagonism with picrotoxin $(6.5 \mathrm{mg} / \mathrm{kg}$, subcutaneously)

\begin{tabular}{lcc}
\hline Compound & Mean effective dose, $\mathrm{ED}_{50^{\prime}} \mathrm{M} \pm \mathrm{m}$ & Curve slope (s) \\
\hline Propoxazepam & $0.37 \pm 0.07 \mathrm{mg} / \mathrm{kg}$ & 0.64 \\
& $(0.9 \pm 0.2 \underline{\mathrm{mmol}} / \mathrm{kg})$ & \\
\hline Flumazenil & $\begin{array}{c}5.24 \pm 2.38 \mathrm{mg} / \mathrm{kg} \\
\end{array}$ & 2.2 \\
\hline Flumazenil + propoxazepam & $2.017 \pm 0.008 \underline{\mathrm{mmol}} / \mathrm{kg})$ & \\
$\begin{array}{l}0.5 \mathrm{mg} / \mathrm{kg}, 95 \% \text { of protective } \\
\text { effect) }\end{array}$ & $(0.007 \pm 0.001 \underline{\mathrm{mmgl}} / \mathrm{kg})$ & 1.7 \\
\hline
\end{tabular}




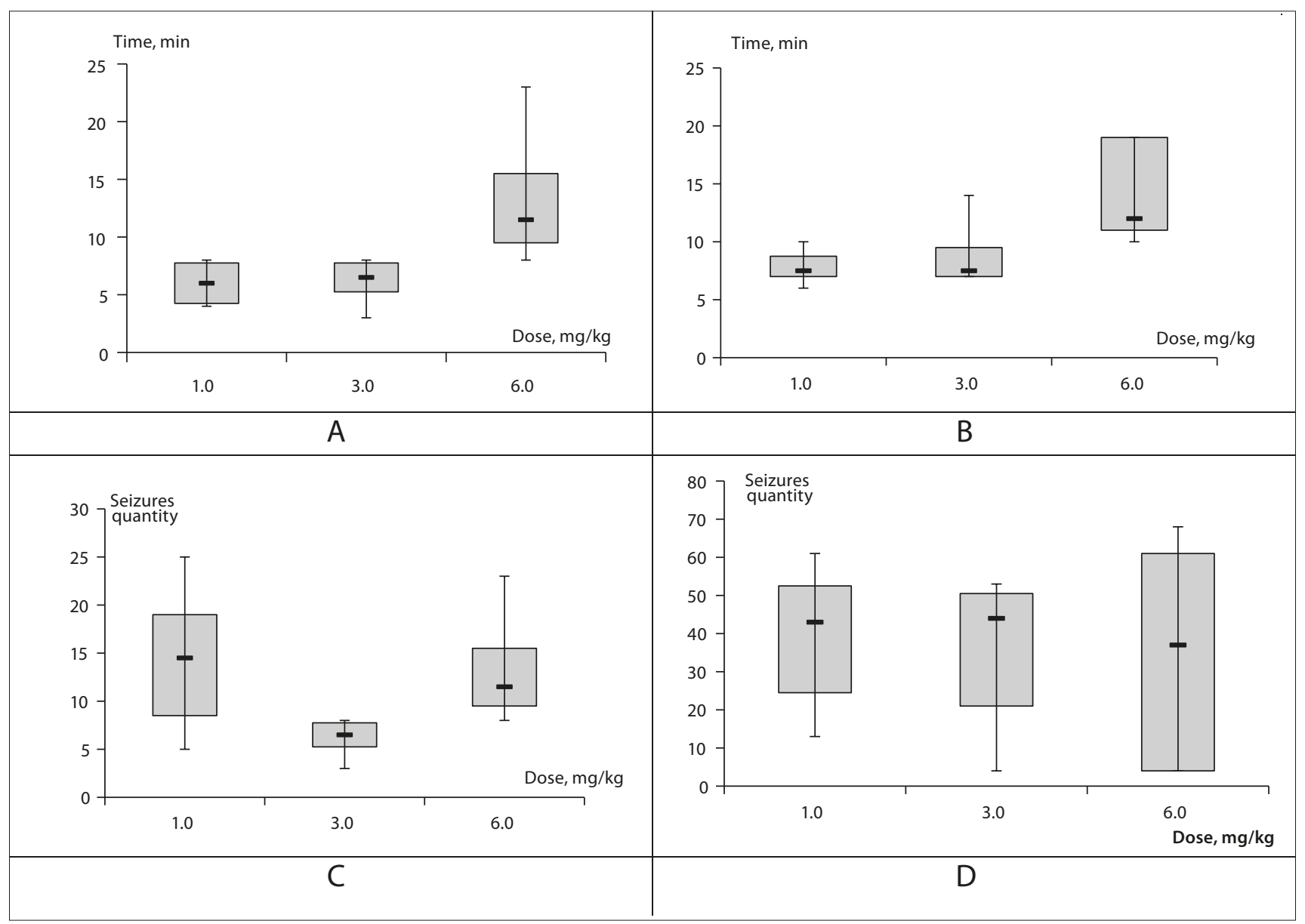

Figure 1. Changes in latency time of myoclonic (A) and tonic (B) seizures and their quantity (C, D) after picrotoxin injection (6.5 mg/kg subcutaneously) after previous flumazenil administration at different doses (intraperitoneally).

Under concomitant administration of flumazenil and propoxazepam, the protective effect of the latter is that it reduces the animals survival indicator, which is important for this experiment design. As flumazenil belongs to the competitive antagonist of the benzodiazepine binding sites, the determined decrease in propoxazepam protective action by $50 \%$, reached at flumazenil dose $2.25 \pm 0.38 \mathrm{mg} / \mathrm{kg}$ $(7.4 \pm 1.3 \mathrm{mmol} / \mathrm{kg})$ in this experimental model, can prove the propoxazepam anticonvulsive action developing mainly through GABA-ergic mechanism. The "dose-effect" curve slope $(1,7)$ can also assume the inclusion of some other mechanisms of action as the initial value (0.64) is changed. The involvement of the glycineergic mechanism is also possible, as shown earlier [4].

Antagonistic interaction between propoxazepam and flumazenil can also have influence on representation of different types of seizure, because the development of excitation and further achievement of the lethal effect are the final stage of interaction of propoxazepam, flumazenil and picrotoxin with GABA-R. This period is also characterized by certain stages which are realized on the physiological level as corresponding convulsions of the skeletal muscles (myoclonic and tonic seizures).

Flumazenil itself at doses from $1-6 \mathrm{mg} / \mathrm{kg}$ increases the time of myoclonic seizures development by approximately up to 2 times (Fig. 1, A).

By both this indicator and latency time of tonic seizures appearance, the flumazenil effect has no statistically significant difference at doses $3 \mathrm{mg} / \mathrm{kg}$ and $1 \mathrm{mg} / \mathrm{kg}$ (Fig. 1 , B). Thus, the similar influence of flumazenil on the latency time increase for different seizures, as well as the absence of dose-dependence inhibition on these seizures (Fig. 1, C, D) also proves the absence of intrinsic activity of flumazenil on picrotoxin-induced seizures. But the certain increase in lifespan of experimental animals can be due to the stabilization effect on GABA-R, which possibly brings about the receptor blocking and impedes interaction with picrotoxin.

Increase of flumazenil dose, administered prior to propoxazepam, does not lead to alteration of the latency time of myoclonic and tonic seizures (Fig. 2, A, B), thus the difference between these indicators, obtained after propoxazepam alone administration $(0.9 \mathrm{mg} / \mathrm{kg})$, is absent. At the same time, flumazenil dose increase leads to an increase in the quantity of myoclonic and tonic seizures (Fig. 2, C, D). There is a possibility that high doses of flumazenil (much higher than those of propoxazepam) have no influence on the time of the appearance of epileptic activity centres, but can stabilize them, diminishing the blocking activity of propoxazepam.

As the power and existence time of the epileptic focus determines the severity of the epileptic state and its final result (lethal effect), the above suggestion is proved by the changes of the total survival time of the animals (Fig. 2, D). Therefore, at the propoxazepam dose of $0.9 \mathrm{mg} / \mathrm{kg}$, lifespan of the mice was $~ 55$ min (16.7\% of lethality, 1 of 6$)$, but flumazenil dose increase not only reduced this value, but 


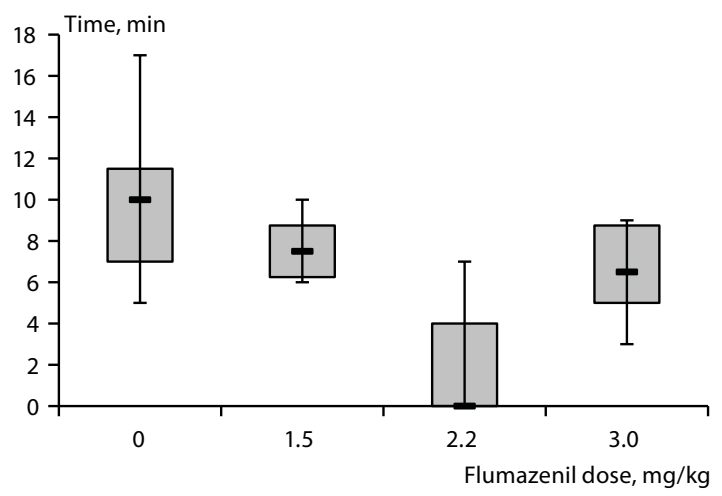

A

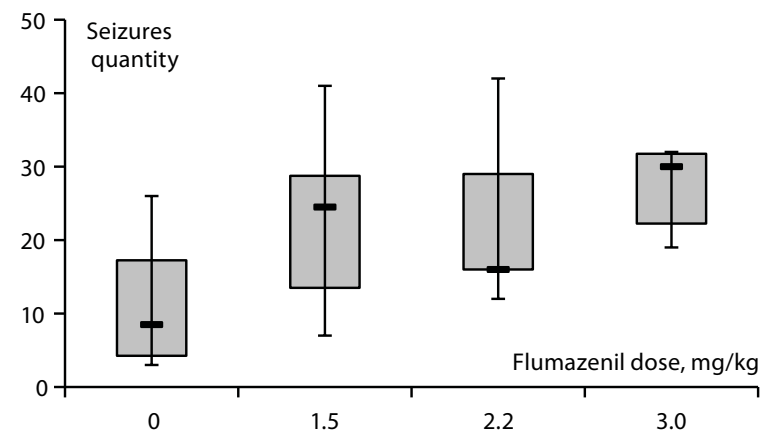

C

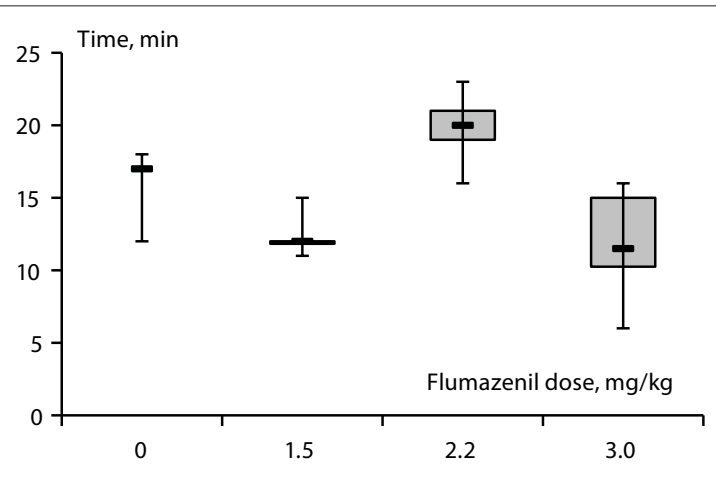

B

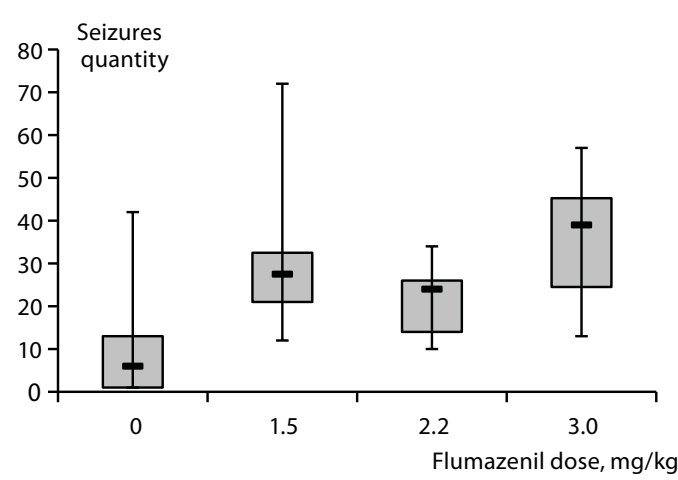

D

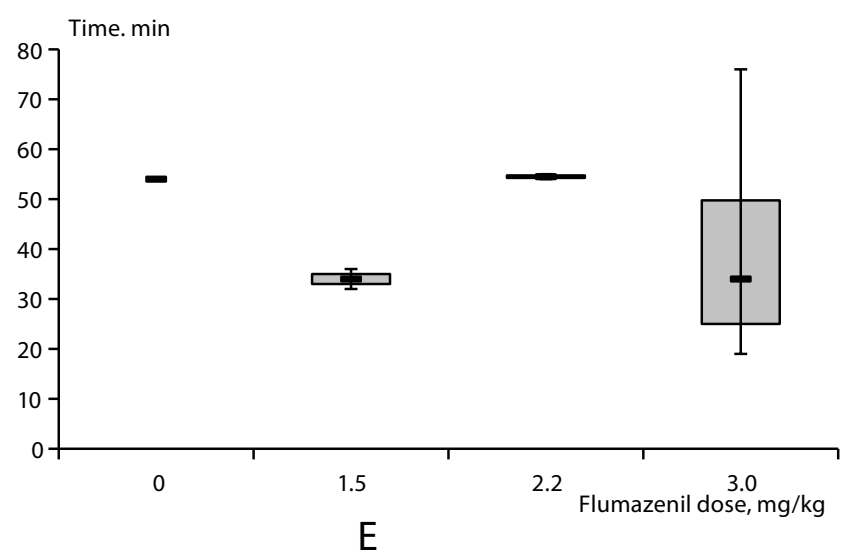

Figure 2. Changes in latency time of myoclonic (A) and tonic (B) seizures and their quantity $(\mathrm{C}, \mathrm{D})$ as well as animals lifespan (E) after picrotoxin injection (6.5 mg/kg subcutaneously) after previous administration of propoxazepam $(0.5 \mathrm{mg} / \mathrm{kg}$ ) and flumazenil at different doses (intraperitoneally)

also increased the dispersion of the experimental data, reflecting the individual variability of central nervous system sensitivity of animals.

In observing that each of the seizure types (myoclonic or tonic) also acts as epileptoformic activity severity, there was estimated the relative (in \%) impact of each seizure type in the total structure of the picrotoxin-induced convulsions (Fig. 3, 4).

The absence of statistically significant flumazenil influence on the picrotoxin-induced seizures appears not only in their latency time, but also in the relative quantity (ratio) of myoclonic and tonic components (Fig. 3, according to
Pearson's chi-square test). The mentioned impact of the more severe tonic component in the control group ( $70 \%)$ has no significant changes, and after flumazenil administration proves that the parallelism of this indicator increases with picrotoxin administration (control), together with the absence of flumazenil intrinsic activity in this model.

On the contrary, propoxazepam administration reduces the severity of picrotoxin-induced convulsions, causing the redistribution of myoclonic and tonic component by up to $50 \%$ (Fig. 4) in the common seizures, compared to the control group (Fig. 3) ( $\mathrm{p} \leq 0.01$ for both myoclonic and tonic components, chi-square test) 


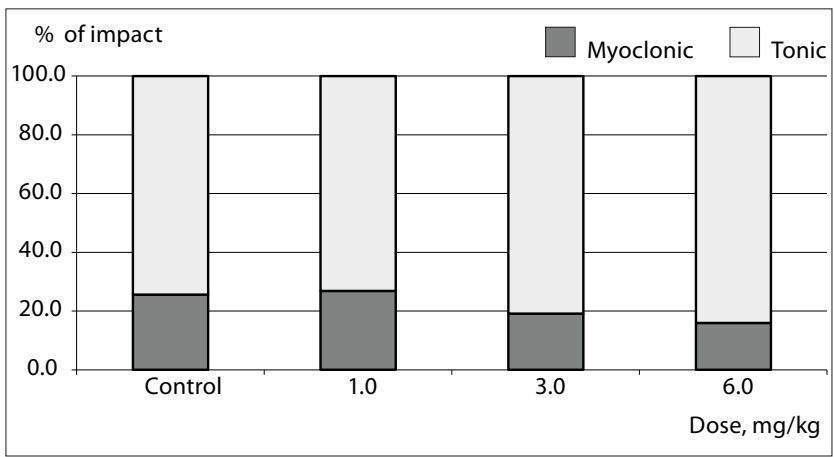

Figure 3. Relative impact of different seizure types (myoclonic and tonic) in the common structure of picrotoxin-induced seizures $(6.5 \mathrm{mg} / \mathrm{kg})$ after flumazenil administration

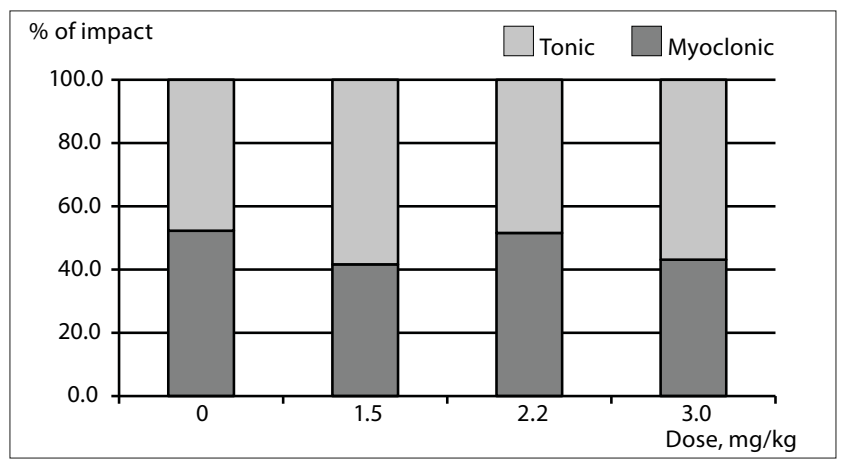

Figure 4. Relative impact of different seizure types (myoclonic and tonic) in the common structure of picrotoxin-induced seizures $(6,5 \mathrm{mg} / \mathrm{kg})$ after flumazenil administration at different doses together with propoxazepam $(0,5 \mathrm{mg} / \mathrm{kg}, 95 \%$ of anticonvulsive action).

Moreover, as revealed during analysis of seizure indices after concomitant propoxazepam and flumazenil administration, the antiseizure effect of propoxazepam in this pharmacological model is stable even under the simultaneous administration with competitive antagonist - flumazenil, which proves the assumption about the inhibitory influence of propoxazepam on the already formed epileptic centres.

Effect of flumazenil on propoxazepam antinociception in tail flick test in rats. At the dose $1 \mathrm{mg} / \mathrm{kg}$, flumazenil did not change the threshold of pain sensitivity of the

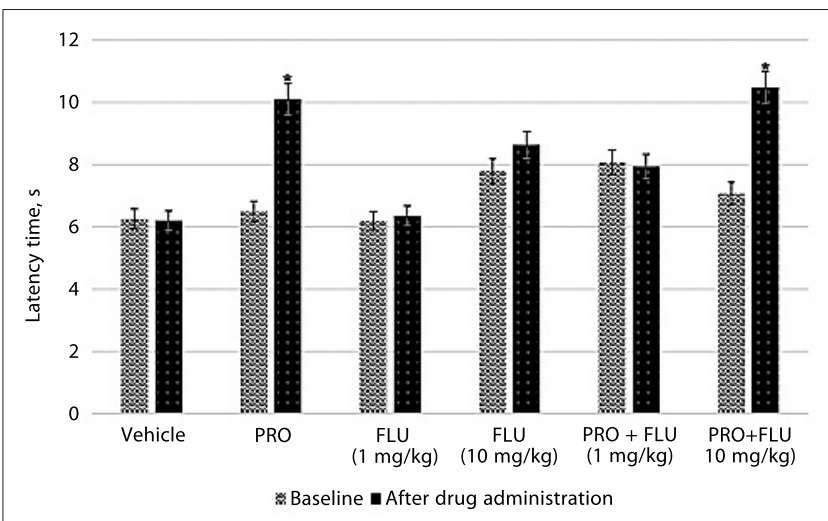

Figure 5. Effect of propoxazepam ( $2 \mathrm{mg} / \mathrm{kg}$, orally) on tail flick latency time in rats under flumazenil pretreatment. Tail flick latency time to heat influence were evaluated before (baseline) and 2 hours after propoxazepam administration. Inhibitor of benzodiazepine receptors (flumazenil) was injected p.o. 0.5 hour before propoxazepam administration. Flumazenil in low dose $(1 \mathrm{mg} / \mathrm{kg}$ ) inhibited analgesic effect of propoxazepam, whereas in high dose $(10 \mathrm{mg} / \mathrm{kg})$ it did not affect propoxazepam-induced analgesia. PRO -propoxazepam; FLU -flumazenil. Data are given as the mean \pm S.D., $n=7$. ${ }^{*} \mathrm{P}<0.05$ versus baseline experimental animals, but the concomitant administration with propoxazepam totally abolished the antinociceptive action of the latter (tail flick latency period changes were $-1.6 \%$, compared to initial levels, and +55.1 compared to propoxazepam administration alone) (Fig. 5, Tab. 2).

In contrast to this, flumazenil at the dose $10 \mathrm{mg} / \mathrm{kg}$ had almost no influence on propoxazepam analgesic action (tail flick latency time increased after their concomitant administration to $+48.0 \%$, compared to initial values), but after its administration alone, even pushed the tendency for own analgesic action which, however, had not reached the statistically significant level (latency period increased up to $10.6 \%$, on average).

Table 2. Propoxazepam analgesic action after oral administration (at $\left.E D_{50}\right)$, together with benzodiazepine receptor antagonist - flumazenil $(\mathrm{M} \pm \mathrm{m}, \mathrm{n}=7)$

\begin{tabular}{|c|c|c|c|c|}
\hline \multirow[t]{2}{*}{ Compound } & \multirow{2}{*}{$\begin{array}{l}\text { Dose, route of admini- } \\
\text { stration }\end{array}$} & \multicolumn{2}{|c|}{ Tail flick latency period, s } & \multirow{2}{*}{$\begin{array}{c}\% \text { in } \\
\text { relation } \\
\text { to the } \\
\text { initial } \\
\text { value }\end{array}$} \\
\hline & & $\begin{array}{l}\text { Initial } \\
\text { value }\end{array}$ & $\begin{array}{l}\text { After admini- } \\
\text { stration } \\
\text { of the } \\
\text { compound }\end{array}$ & \\
\hline $\begin{array}{l}\text { Control } \\
\text { (solvents) }\end{array}$ & - & $6.25 \pm 0.29$ & $6.21 \pm 0.27$ & $-0.4 \%$ \\
\hline Propoxazepam & $1.82 \mathrm{mg} / \mathrm{kg}$ orally & $6.50 \pm 0.30$ & $10.1 \pm 0.29^{*}$ & $+55.1 \%$ \\
\hline Flumazenil & $1 \mathrm{mg} / \mathrm{kg}$ intraperitoneally & $6.19 \pm 034$ & $6.36 \pm 0.33$ & $+2.7 \%$ \\
\hline Flumazenil & $10 \mathrm{mg} / \mathrm{kg}$ intraperitoneally & $7.80 \pm 0.44$ & $8.63 \pm 0.47$ & $+10.6 \%$ \\
\hline $\begin{array}{l}\text { Flumazenil + } \\
\text { Propoxazepam }\end{array}$ & $\begin{array}{c}1 \mathrm{mg} / \mathrm{kg} \text { intraperitoneally } \\
1.82 \mathrm{mg} / \mathrm{kg} \text { orally }\end{array}$ & $8.07 \pm 0.40$ & $7.94 \pm 0.40$ & $-1.6 \%$ \\
\hline $\begin{array}{l}\text { Flumazenil + } \\
\text { Propxazepam }\end{array}$ & $\begin{array}{c}10 \mathrm{mg} / \mathrm{kg} \text { intraperitoneally } \\
1.82 \mathrm{mg} / \mathrm{kg} \text { orally }\end{array}$ & $7.08 \pm 0.53$ & $10.48 \pm 0.72^{*}$ & $+48.0 \%$ \\
\hline
\end{tabular}

* Statistically significant difference $(p<0.05)$, compared to initial level.

\section{DISCUSSION}

Picrotoxin was chosen as the pharmacological probe in this study because it acts as an inter-channel non-competitive antagonist of GABA-R. Reduction of picrotoxin-induced seizures is assumed to be due to the biotarget associated inhibitory activity of the studied substance.

Flumazenil, a 1,4-imidazodiazepine derivative, is a specific antagonist-agonist of the benzodiazepine site of GABA-R [12], and is used in medicine as an antidote for benzodiazepine overdose. When used at therapeutic doses, flumazenil manifests no intrinsic activity or neuroactive properties, which determines its definition as a GABA-R antagonist. But its binding to the receptor complex can stabilize it to some degree, which leads to manifestation of its own intrinsic activity at higher doses. Flumazenil has no influence on peripheral GABA-ergic systems and does not change the blood concentration, bioavailability and elimination half-life of other benzodiazepines [13]; its action depends totally on the antagonistic process in GABA-R [14].

On a different animals species, flumazenil demonstrated negligible anticonvulsant activity in the range of doses $2-50 \mathrm{mg} / \mathrm{kg}$ [15]. These effects were noticeably lower compared to those of other benzodiazepines. In most cases, the dose-dependent anticonvulsive effect reduction of benzodiazepines is registered when used together with flumazenil, and there is no interferention with sodium 
valproate and phenobarbital effects [16], which proves the flumazenil regulation at GABA-R benzodiazepine site. The above-mentioned suggests the validity of flumazenil use as pharmacological trial for studying novel molecules regarding the GABA-R.

For estimating the antagonistic interaction between propoxazepam and flumazenil in vivo, the following experiment design has been suggested: intraperitoneal administration of flumazenil in different doses (1.5-2.2$3.0 \mathrm{mg} / \mathrm{kg})$ concomitantly with propoxazepam $(0.5 \mathrm{mg} / \mathrm{kg}$, calculated $\mathrm{ED}_{95}$ ) to mice 0.5 hours prior to subcutaneous picrotoxin administration. The route of administration and time provide the fast and full entry of the substances into the body (bioavailability up to $100 \%$ ), and maintains their ration determined by the used doses. The abovementioned reduces the impact of elimination processes since flumazenil is excreted faster $\left(\sim 0.53-0.99\right.$ hour $\left.^{-1}\right)$ [17], compared to propoxazepam $\left(0.02\right.$ hour $\left.^{-1}\right)$ [18]. The chosen dose of propoxazepam ensures the anticonvulsive (protective) effect in 95\% of experimental animals in this seizure model. Thus, the change of $\mathrm{ED}_{50}$ is the indicator of anticonvulsive action of propoxazepam, independent from GABA-R functioning, and the process characteristics (mean effective dose and curve slope) reflect the interaction between them. If additivity occurs, $100 \%$ of the anticonvulsive action in all the experimental groups is registered. Presumably the competitive interaction with flumazenil and propoxazepam on the level of benzodiazepine binding sites of GABA-R will lead to reduction in the protective (anticonvulsive) action, and will induce the appearance of different seizures types as well as the lethal effect. In the case that flumazenil under this pharmacological model has no the estimated effect, its dose which reduces propoxazepam effect to $50 \%$ (ED $_{50}$ under concomitant administration) can be the indicator of the relative affinity of flumazenil and propoxazepam to the GABA-R in vivo.

Thus, the ability of flumazenil to diminish the anticonvulsive action of propoxazepam assumes that the mentioned mechanism involves the GABA-ergic level and benzodiazepine site activation, which in agreement with previously conducted studies. Therefore, on the model of chemically induced seizures the mean effective doses of propoxazepam [8] on antagonism with picrotoxin ((1.67 $\pm 0.09 \mathrm{mg} / \mathrm{kg})$, pentylenetetrazole $(0.9 \pm 0.04 \mathrm{mg} / \mathrm{kg})$ and strychnine $(14.24 \pm 0.47 \mathrm{mg} / \mathrm{kg}))$ were determined, which suggests the high activity of the tested substance. On the dose-effect curves data using the comparative quantile analysis for the mentioned chemoconvulsants, the different stages of the substance interaction with GABA and glycine receptors in vivo were hypothesized. The obtained data assume the presumable realization of propoxazepam anticonvulsive action through GABA-ergic mechanism. Glycinergic mechanisms which participate in strychnineinduced seizures inhibition are involved at propoxazepam doses which exceed the $\mathrm{ED}_{50}$ and, possibly act as an additional part of the anticonvulsive action. The obtained data [8] have been proved in in vitro experiments determination the propoxazepam binding with rat brain synaptosomes ( $\mathrm{K}_{\mathrm{i}}$ of specific binding of $\left[{ }^{3} \mathrm{H}\right]$ flumazenil is $3.5 \pm 0.3 \mathrm{nmol}$ ). According to the GABA shift, the substance belongs to the full GABA-R agonists.

To study the spinal antinociceptive action, the tail flick test ase performed. This model, like the hot plate test, measures animal nociceptive response latencies to thermal stimulus, but tail flick is principally a spinal response whereas the hot plate is predominantly supraspinal. In the tail flick test, propoxazepam was equal to that exceeded by both intensity and duration of the effect of the reference drug (ketorolac) under the similar doses and administration conditions [19]. Nonsteroidal anti-inflammatory drugs (NSAIDs), such as ketorolac, cause gastrointestinal complications, e.g. ulcers and erosions. The pathophysiology of these complications has mostly been attributed to NSAID's action on the cyclooxygenase (COX) inhibition and the subsequent prostaglandin (PG) deficiency. PGs play a key role in gastric epithelial defence by enhancing the pre-epithelial, epithelial, post-epithelial defence mechanisms: PGs regulate the secretion of bicarbonate and mucous, inhibit gastric acid secretion, and are important in maintaining epithelial cells restitution and mucosal blood flow. NSAIDs can damage the gastrointestinal tract, causing widespread morbidity and mortality[19]. Propoxazepam had no damaging influence on the stomach after acute, subacute and chronic administration, nor did it alter alimentary behaviour and total animals activity, which differerentiates it from ketorolac on the action mechanism and proves the harmlessness of this compound in particular for the gastrointestinal tract [20]. Unlike ketorolac, which acts through prostaglandin synthesis inhibition, propoxazepam has a central mechanism of pain control through the GABA-ergic system, as confirmed in experiments with flumazenil.

Flumazenil is a GABAA-receptor benzodiazepine site neutral allosteric modulator, selective antagonist of a1subunit, and partial agonist of a4-subunit, that determine its anticonvulsive and analgesic action [17]. It is possible that the flumazenil dose increase leads to the prevailing of the agonistic influence on this part of the GABA-receptor, as well as in the case of propoxazepam, since for flumazenil has shown both antinociceptive and anticonvulsive actions [5] through GABA-receptor complex stabilization.

Therefore the mechanism of the antiseizure and antinociceptive actions of propoxazepam is due its interaction with GABA-R. At the same time, the analgesic action of propoxazepam also involves different biotargets.

The possible role of different receptors on propoxazepam effects was also studied [21]. Naloxon, prazosin, clonidine, yohimbine, isoproterenol, propranolol, nalbuphine, chlorpromazine, dopamine, memantine, magnesium sulfate and phenylephrine were used as the pharmacological analyzers. Propoxazepam was administered orally $\left(1.83 \mathrm{mg} / \mathrm{kg}, \mathrm{ED}_{50}\right.$ of analgesic activity). A detailed study of the realization mechanisms of propoxazepam analgesic action was conducted under bradykinin, zymosan and carrageenan-induced hyperalgesia in the tail-flick model.

The results showed that propoxazepam reduced the pain reaction caused by bradykinin and zymosan, had almost no effect on carrageenan-induced hyperalgesia. In the tail-flick model, it was proved that the opioid system was not involved in the action of this compound. The current study has demonstrated that the dopaminergic and adrenergic systems were also involved in the mechanisms of propoxazepam activity, particularly alpha-adrenergic receptors. Using NMDA-receptors antagonist of magnesium sulfate, but not memantine, under conditions of its compatible introduction with propoxazepam, increased its analgesic effect. 


\section{CONCLUSIONS}

Benzodiazepines are commonly abused. This abuse is partially related to the toxic effects that they produce and also to their widespread availability. Serious illness and death rarely result from benzodiazepine abuse alone; however, they are frequently taken with either alcohol or other medications. The combination of benzodiazepines and alcohol can be dangerous, and even lethal.

The last year on $\mathrm{GABA}_{\mathrm{A}}-\mathrm{R}$ research revealed that the individual pharmacological effects of benzodiazepines are mainly determined by the a subunits contained in the targeted receptor, and their anatomical distribution in the nervous tissue. Sedation and anticonvulsive effects are mainly caused by benzodiazepine binding to the al subtype, while the anxiolytic effects were very recently shown for the modulation of a2-containing, and for the a5-containing GABAA receptors [22]. Muscle relaxation results from binding to the a2-and a3-GABAA receptor subtypes, while motor coordination is impaired by modulation of a1 or a3 receptor subtypes [23]. The a5 subunit is additionally involved in learning and memory [24].

The benzodiazepine binding site antagonist flumazenil has a similar a-subunit selectivity profile to diazepam [25].

Anxiety disorders are some of the most frequently diagnosed disorders in psychiatric medicine worldwide. Although conventional benzodiazepines are effective anxiolytics, their use is restricted in part because of the occurrence of undesirable side-effects. The identification of $\alpha 2$ and $3 \mathrm{GABA}_{\mathrm{A}}$ - $\mathrm{R}$ in the brain is important for mediating the anxiolytic effects of benzodiazepines, and intrinsic efficacy at this receptor subtypes is sufficient for a benzodiazepinetype compound to possess some abuse potential. The antihyperalgesic effect of benzodiazepines depends mainly on a2-containing $\mathrm{GABA}_{\mathrm{A}}-\mathrm{R}$ in the spinal cord [26].

In observing that the specific pharmacological actions of propoxazepam are anticonvulsant (a1 subtype $\mathrm{GABA}_{\mathrm{A}}-\mathrm{R}$ ) and analgesic (a2 subtype $\mathrm{GABA}_{\mathrm{A}}-\mathrm{R}$ in the spinal cord), it can be suggested that the substance has no abuse-related side-effects.

The possibility of new 1.4-benzodiazepine derivatives possessing the affinity to certain subunits of $G_{A B A}-R$ allowed to obtain effective medicines in different countries. Thus, in 2015, Metizolam, Nitrazolam, Cloniprazepam and Adinazolam were synthesized and studied, followed in 2016 by Flunitrazolam, Fonazepam and Norflurazepam [27].

\section{REFERENCES}

1.Löscher W, Schmidt D. Which animal models should be used in the search for new antiepileptic drugs? A proposal based on experimental and clinical considerations. Epilepsy Res. 1988; 2(3): 145-181.

2.Deshmukh R, Thakur A. S, Dewanga D. Mechanism of action of anticonvulsant drugs: a review. Int. J. Pharm. Sci. Res. 2011; 2(2): 225-236.

3.Zeilhofer HU. The glycinergic control of spinal pain processing. Cell Mol Life Sci., 2005; 62: 2027-2035. https:/doi.org/ 10.1007/s00018005-5107-3.

4. Knabl J, Zeilhofer UB, Crestani F, Rudolph U, Zeilhofer HU. Genuine antihyperalgesia by systemic diazepam revealed by experiments in GABAA receptor point-mutated mice. Pain, 2009; 141(3): 233-238. https://doi.org/10.1016/j.pain.2008.10.015

5. Golovenko NYa, Voloshchuk NI, Andronati SA, Taran IV, Reder AS, Pashynska OS, Larionov VB. Antinociception induced by a novel benzodiazepine receptor agonist and bradykinin receptor antagonist in rodent acute and chronic pain models. European Journal of Biomedical and Pharmaceutical sciences, 2018; 5(12): 79-88.
6. Larionov VB, Reder AS. Propoxazepam, a novel analgesic with multifunctional mechanism of action: review of preclinical data. International scientific and practical conference «Prospects for the development of medicine in EU countries and Ukraine», Wloclavek, Republic of Poland, December 21-22, 2018. P.111-115.

7. Desai A, Kherallah Y, Szabo C, Marawar R. Gabapentin or pregabalin induced myoclonus: A case series and literature review. J Clin Neurosci. 2019; 61: 225-234

8. Golovenko NYa, Larionov VB, Andronati SA, Valivodz' IP, Yurpalova T. A. Pharmacodynamic analysis of propoxazepam interaction with GABA-benzodiazepine-receptor-ionophore complex. Neurophysiology. 2018; 50(1): 2-11.

9. Golovenkol N. Ya. Larionov V. B, Reder A. S, Valivodz I. P. An effector analysis of the interaction of propoxazepam with antagonists of GABA and glycine receptors. Neurochemical Journal, 2017; 11(4): 302-308.

10. Reder A. S. Dispersed substance 7-bromo-5-(o-chlorophenyl)-3propiloxy-1,2-dihydro-3H-1,4-nebzodiazepine-2-one (I) with at least $50 \%$ volume fraction of particles less than $30 \mu \mathrm{m}$ for use as anticonvulsive and analgesic drug. Patent UA 118626.

11. Kawakita K, Funakoshi M. A quantitative study on the tail flick test in the rat. Physiol Behav. 1987; 39(2): 235-40.

12. Hunkeler W, Mohler H, Pieri L, et al. Selective antagonists of benzodiazepines. Nature. 1981; 290: 514-516.

13. Klotz U, Ziegler G, Ludwig L, Reimann I. Pharmacodynamic interaction between midazolam and a specific benzodiazepine antagonist in humans. J Clin Pharmncol.1985; 25: 400-406.

14. O’boyle C, Lambe R, Darragh A, Taffe W, Brick I, Kenny M. RO 151788 antagonizes the effects of diazepam in man without affecting its bioavailability. Br J Anaesth. 1983; 55: 349-356.

15. Kauima M, Lasalle G, Rossler I. The partial benzodiazepine agonist properties of RO 15-1788 in pentylenetetrazol-induced seizures in cats. Eur J PharmncoI1983; 93: 113-115.

16. Nutt OJ, Cowen PJ, Litfle HJ. Unusual interactions of benzodiazepine receptor antagonists. Nature 1982; 295: 436-438.

17. Klotz U, Kanto J. Pharmacokinetics and clinical use of flumazenil (Ro 15-1788). Clin Pharmacokinet. 1988; 14(1): 1-12.

18. Golovenko NYa, Larionov VB, Valivodz' I P. Absorption and distribution of 14C-propoxasepam after its intragastral administration. Physiol Zh. 2017; 63(3): 40-48.

19. Takeuchi K. Prostaglandin E prevents indomethacin-induced gastric and intestinal damage through different EP receptor subtypes. J Physiol. Paris, 2001; 95(1-6): 157-163.

20. Voloshchuk NI, Taran IV, Reder AS, Golovenko MYa. Experimental study of ulcerogenic action of propoxazepam. Reports of Vinnytsia National Medical University. 2018; 22(1): 6-9. doi: 10.31393/reportsvnmedical-2018-22(1)-01

21. Voloshchuk NI, Reder AS, Golovenko MY, Taran IV, Pashinska OS. Pharmacological analysis of neurochemical antinociceptive mechanisms of propoxazepam action. Pharmacology and drug toxicology. 2017; 1(52): 3-11.

22. Rudolph U, Möhler H, 2014. GABAA receptor subtypes: Therapeutic potential in Down syndrome, affective disorders, schizophrenia, and autism. Annual Review of Pharmacology and Toxicology 54, 483-507. http://dx.doi.org/10.1146/annurev-pharmtox-011613-135947

23. Ralvenius WT, Benke D, Acuna MA, Rudolph U, Zeilhofer HU, 2015. Analgesia and unwanted benzodiazepine effects in point-mutated mice expressing only one benzodiazepine-sensitive GABAA receptor subtype. Nat Commun 6, 6803. http://dx.doi.org/10.1038/ncomms7803.

24. Ghafari M, Falsafi S. K, Szodorai E, Kim E. J, Li L, Hoger H, Berger J, Fuchs K, Sieghart W, Lubec G. Formation of GABAA receptor complexes containing alphal and alpha5 subunits is paralleling a multiple T-maze learning task in mice. Brain Struct Funct. 2016; 222(1): 549-561 http:// dx.doi.org/10.1007/s00429-016-1233-x.

25. Rowlett J. K, Platt DM, Lelas S, Atack JR, Dawson GR. [Different GABAA receptor subtypes mediate the anxiolytic, abuse-related, and motor effects of benzodiazepine-like drugs in primates. PNAS 2005; 102(3): 915-920.

26. Ralvenius WT, Acuna MA, Benke D, Matthey A, Daali Y, Rudolph U, Desmeules J, Zeilhofer HU, Besson M. The clobazam metabolite $\mathrm{N}$-desmethyl clobazam is an alpha2 preferring benzodiazepine with an improved therapeutic window for antihyperalgesia. Neuropharmacology 2016; 109: 366-375. http://dx.doi.org /10.1016/j. neuropharm. 2016.07.004

27. Bjoern Moosmann, Volker Auwärter. Designer Benzodiazepines: Another Class of New Psychoactive Substances. Springer International Publishing AG, part of Springer Nature 2018. Handbook of Experimental Pharmacology, https://doi.org/10.1007/164. 2018-154 